\title{
Disturbances of sexual potency in patients with basilar impression and Arnold-Chiari malformation ${ }^{1}$
}

\author{
M. CAETANO DE BARROS, W. FARIAS DA SILVA, \\ H. C. DE AZEVEDO FILHO, AND C. SPINELLI \\ From the Institute of Neurology and Neurosurgery, \\ Federal University of Pernambuco, Brazil
}

SYNOPSIS Sexual impotence is common in patients with basilar impression and/or Arnold-Chiari malformation. There is no evidence of hypogonadism and testicular biopsy is usually normal. An autonomic disturbance is postulated.

Basilar impression and the Arnold-Chiari malformation are frequently found in the north-east of Brazil. Our experience is represented by 100 patients operated on with one or other of these malformations or more frequently by an association of both conditions. In addition to the neurological syndrome caused by these congenital malformations, we recently had our attention drawn to the high frequency of sexual disturbances ranging from reduction to complete loss of sexual potency.

In our series of 65 cases published in 1968 (De Barros et al., 1968) involvement of sexual potency was present in $28 \%$. By investigating more rigorously the history of these patients we later discovered that sexual difficulties are present in almost every case.

\section{METHOD}

To clarify the possible causes of these disturbances we chose a group of the 20 last patients operated on, all with complaints in the sexual sphere and we started an investigation, which is still continuing, including some laboratory tests, and the results of these studies will be analysed here.

Nineteen were male, all young. Eleven of them $(57.8 \%)$ had an upper age limit of 35 years. All had basilar impression associated with Arnold-Chiari malformation except two patients who had basilar impression alone.

1 Paper presented at the World Congress of Neurological Sciences, Tokyo, October 1973.

(Accepted 3 February 1975.)
The beginning of the neurological disturbances was closely followed by the onset of sexual complaints, but in some patients sexual complaints appeared first by a variable number of years, reaching a maximum of six years in two cases (Table).

All of the patients had sexual frigidity and al|ळ male patients had reduced potency of differento degrees. However, 10 of them were completely impotent at the time of examination. Three of these $c$ $10 \mathrm{had}$ married and procreated before becomingo impotent, and four of the patients who complainesk of reduction of potency had offspring (Table). 흔

Some clinical laboratory examinations were or carried out (Table). A glucose tolerance test showed a diabetic-like curve in only three patients. The serum protein bound iodine level was normal in all 20 cases and the serum cholesterol in 19 cases.

A water overload test was normal in the 19 cases examined. Determinations of 17-ketosteroids and 17hydroxy'steroids carried out on the urine of 10 patients were normal. Urinary oestrogens, determined in only three patients, were also normal. Four patients from whom material could be obtained had oligospermia. Testicular biopsy was performed on all 19 patients immediately after craniectomy under general anaesthesia.

In 16 cases no histological alterations were found and consequently were considered normal.

In case 2 , a patient aged 42 years who was impotent, focal lesions of tubular atrophy were found. In case 12, aged 26 years, with reduction of sexual potency, atrophy of the seminiferous epithelium was encountered (Table).

Finally, in case 14, a patient aged 25 years who was impotent, the histological sections revealed an arrest of cellular differentiation and an absence of 598 


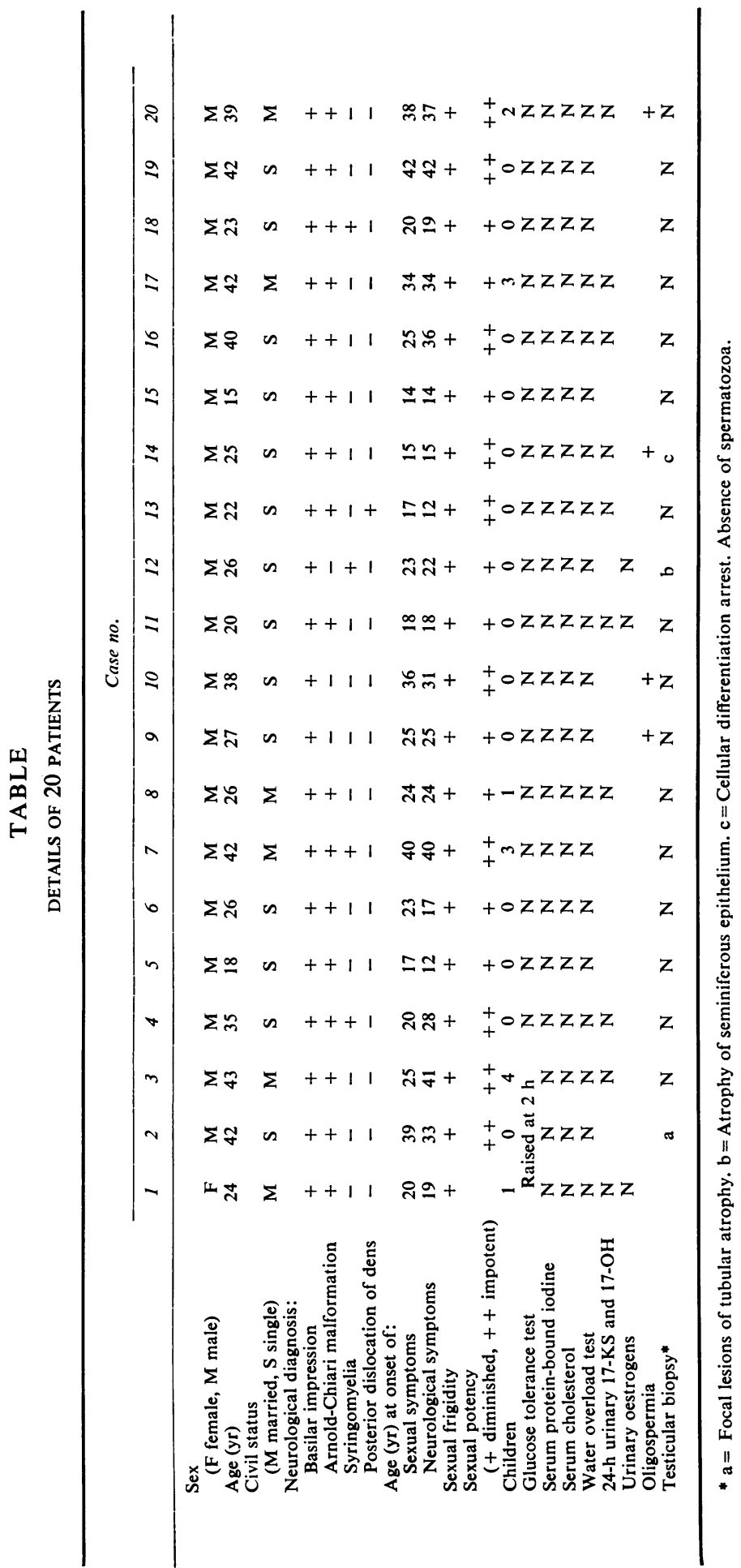


spermatozoa. However, in none of the cases were there alterations of the interstitial cells of Leydig.

Chromosomal studies were performed with peripheral blood cultures obtained from four patients and a normal XY/46 pattern was found.

\section{COMMENTS AND CONCLUSIONS}

References to disturbances of sexual potency in the symptomatology of patients with basilar impression and/or Arnold-Chiari malformation are very rare. Garcin and Oeconomos (1953) briefly mentioned the fact and suggested that the impotence could result from a 'hypothalamichypophysial repercussion of the original cranial spinal malformation'.

From the studies we have made up to the present time, no satisfactory explanation has as yet been obtained for the deficit of sexual potency in these patients. However, we think we can draw some provisional conclusions.

1. Sexual impotence is a frequent symptom of patients with basilar impression and/or ArnoldChiari syndrome.

2. Sexual deficit does not appear to be the result of a hypogonadism in connection with a pituitary or hypothalamic involvement since the patients studied show neither clinical nor laboratory signs of hypogonadism.
3. The testicular lesions found in the histological sections are relatively rare and cannot be considered responsible for the reduction or abolition of sexual potency.

4. The reduction of sexual potency could be the result of disturbances of the irrigation of the erectile tissue of the penis by alterations of the sacral parasympathetic and/or lumbar sympathetic innervation. These disturbances of the autonomic innervation of the vessels of the cavernous bodies could depend primarily on a disorder of the parasympathetic control coming from the hypothalamus. However, proof of this hypothesis is lacking.

Perhaps this suggestion is not valid and we do oै not completely know the causes of the altera- $\overrightarrow{0}$ tions of sexual potency in case of basilar impression and Arnold-Chiari syndrome. The osseous and nervous lesions may be independent phenomena within the syndrome.

\section{REFERENCES}

De Barros, M. C., Farias, W., Ataide, L., and Lins, (1968). Basilar impression and Arnold-Chiari malformat tion. A study of 66 cases. Journal of Neurology, Neuro surgery, and Psychiatry, 31, 596-605.

Garcin, R., and Oeconomos, D. (1953). Les Aspects Neuro logiques des Malformations Congénitales de la Charnièreg Cranio-rachidienne. Masson: Paris. 